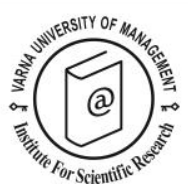

\title{
Sense of Place of Host Community in Tourism Development: The Case of Tunku Abdul Rahman Park, Sabah
}

\author{
Paulin P.L. Wong ${ }^{1}$ \\ Received: 04/03/2019
}

\begin{abstract}
${ }^{1}$ Universiti Malaysia Sabah, Faculty of Business, Economics and Accountancy, Jalan UMS, 88450, Kota Kinabalu, Sabah, Malaysia. Phone: +6088320000. Email: paulinwongpl@gmail.com
\end{abstract}

Coordinating editor: Faizan Ali

Supervisors: Dr. Balvinder Kaur Kler

Institution awarding the Ph. D. Degree: Universiti Malaysia Sabah, Malaysia

Date of defence: 28/08/2018

Citation: Wong, P. (2019) Sense of Place of Host Community in Tourism Development: The Case of Tunku Abdul Rahman Park, Sabah. Doctoral Dissertation Summary. European Journal of Tourism Research 23, pp. 212-216

\section{Goal and objectives of the dissertation}

Goal

This study aims at contributing to the theory of Place specifically in the context of tourism development in a national park and provides an understanding of how a host community feels about changes to place. Sense of Place (SoP) is the emotional, cognitive and functional bonds with place. Understanding place meanings provides an insight into the uniqueness of place, and informs peopleplace relationships. Host community place meanings could contribute to destination sustainability by balancing the role of tourism and conservation of national parks if incorporated into the parks management plans. Therefore, the goal of this dissertation is to identify and interpret the experiences and relationships of the host community in
Kota Kinabalu towards Tunku Abdul Rahman Marine Park (TARP) in Sabah, Malaysia as it transforms from a local recreation site into an international tourist destination and faces increasing demand for activities and space.

\section{Objectives}

This study raises the need to identify and interpret the experiences and relationships of the host community who visit TARP for leisure and recreation. The need to understand these attachments for host community in light of tourism development at TARP led to the general research question of this study:

What SoP does the host community have for TARP? To answer this question, three research objectives were derived:

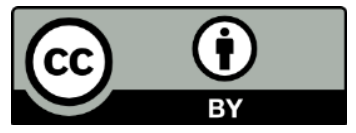

212
This work is licensed under the Creative Commons Attribution 4.0 International (CC BY 4.0). To view a copy of this license, visit https://creativecommons.org/licenses/by/4.0/ 
i. To identify and interpret the meaningful experiences of TARP for the host community.

ii. To describe the relationships of host community with TARP in relation to their experiences.

iii. To explain the transformation of host community relationships to TARP in tourism development.

\section{Methodology}

This study employed an interpretive inquiry paradigm and used an original and innovative amalgamation of qualitative methods - an adapted Q-method, photo-elicitation techniques and focus group interviews to collect data to understand host-TARP experiences and relationships. Inserting Qsort (the adapted Q-method) into the equation of focus group and photo-elicitation result in the sorted photographs' ability to represent the focus groups thus addressed a gap in Method that uses the combination of pictorial and verbal measures. Besides strengthening the trustworthiness of this study through method triangulation and the added benefits of visual image to evoke memories, this combination of methods introduces a methodological contribution by solving the problem of using visual or pictorial measures for a group.

Four groups of homogenous purposive sample consisting five individuals each were derived which encompassed specific groups of host community including the Generation$X$, Generation- $Y$, tourism industry employees, and expats who have been living in Kota Kinabalu for a minimum of 5 years. They participated in a two-part data collection that includes focus group interviews and visits to TARP to take photographs of meaningful scenes for each group. Eight sets of transcriptions and two hundred fifty photographs were derived for analysis while ATLAS.ti 7 qualitative data analysis software was used for data interpretation. A total of 113 codes were created from 1407 quotations coded in the software programme. The codes were then sorted based on similarities and were assigned to different groups which resulted in the sub-themes and negative themes derived for this study. Considering the meanings for each sub-theme, they are then assembled to form the main themes. The 'essence' of each theme indicated both positive and negative meanings.

\section{Results}

The study's findings are summarized in Figure 1.

Results derived include five main positive themes with two sub-themes each: 'Hedoniaseeking'; 'Aesthetics Appreciation'; 'Companionship'; 'Ephemeral Escapade'; 'Being Host' and three negative themes: 'Crowdedness', 'Observing Island Changes', and 'Underwater Devastation'. These themes produced first, the TARP Host Meanings framework, which validates and refined the Tripartite Sustainability Place Model for Tourist Sites by Pearce (2005), albeit for hosts. Secondly, a Place-based Typology of Host Community Visitors was also derived based on an engagement-estrangement continuum with four categories and demonstrates their relationship with TARP: 'Enthusiast', 'Associate', 'Ambivalent' and 'Disconnected'. These categories are distinguished based on: i) TARP Encounters, ii) Intensity of Place Meanings, iii) Attitude, iv) Host Meanings Attributes, v) Behaviour and vi) Impact. The Place Meanings Matrix (PMM) addresses the transformation of relationships with TARP due to tourism in line with the dynamic nature of SoP. The PMM considers how relationships between people and places transform due to changes at a destination, mainly as it evolves from a recreational place into a tourism destination.

\section{Theoretical conclusions}

This study contributes to Place theory. The TARP Host Meanings framework provides an understanding of place meanings and attributes that needs to be preserved amidst tourism development to avoid negative impacts for the host community and can be used to promote quality on-site experiences for tourists. This study provides a higher order interpretation of the activities, resources and conceptions of Place contextual to TARP, an approach that is unique to the current literature. Moreover, the framework also iden- 
Sense of Place of Host Community in Tourism Development:The Case of Tunku Abdul Rahman Park, Sabah. Doctoral Dissertation Summary.

TARP Host Meanings framework
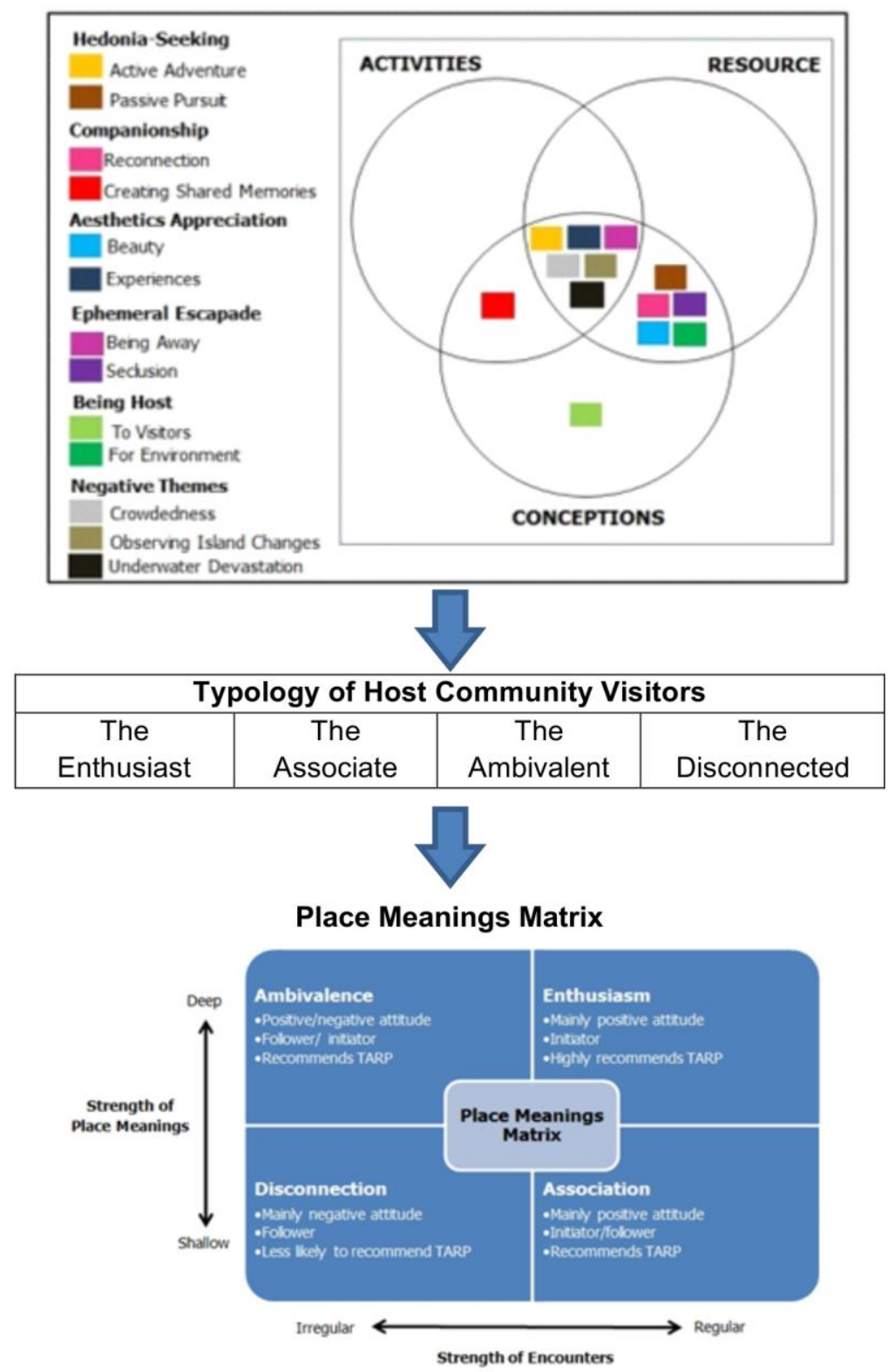

Figure. 1

tified negative place meanings attributes within its place dimensions that contributes to the limited tourism literature on negative place experiences.

The place meanings demand typology built on the work of previous researchers and on Erik Cohen's (1972) sociological tourist typology. Since previous work looked at residents as a whole, and little mention was made of residents being non-homogenous (Krippendorf, 1987), knowledge of this typology contributes to the understanding that any form of tourism development in a national park should consider the diverse range of users, and assess the appropriateness of development accordingly. 
Finally, a matrix projected how relationships with place evolve overtime due to on-site changes, a notion that was previously unexplored in the literature. While previous literature such as Doxey's (1976) Irridex similarly considered resident's feelings towards increase of tourists at a destination, no projections were made prior to tourism development and assume homogenous pretourism emotions among residents. Although the findings are contextualised to this study and not generalizable, future work could test the propositions within the PMM.

This study contributes to the theoretical base on parks planning using SoP. All three outcomes enlighten hosts relationship to their recreation destination, a form of 'host placegaze'. Findings also contribute to the literature on SoP by improving understanding of a stakeholder in the tourism system that is understudied - the host community.

\section{Practical application of the dissertation}

This exploratory study suggests that SoP should be considered as one of the main direction in developing tourism at national parks. Findings propose that future park planning should consider host community, the local stakeholder first. Preserving local SoP could create the authenticity tourists seek in an increasingly similar world. SoP could communicate the uniqueness and emotional tone of a destination. The framework, typology and matrix presented here could be used to improve destination branding and create a toolkit for tour operators. Most of all, the preservation of place meanings is vital to ensure host community, the residentstakeholder does not move from Enthusiasm to Disconnection in how they feel about TARP. The sum total of the findings of this study are useful for the parks management as these could be incorporated into management plans, inform landscape interpretation and destination branding for marine parks now and in the future.

\section{Content of the dissertation}

\section{Abstract of Chapter 1}

The rationale of the study was first described where national parks were defined and elucidated as they transform into tourist destinations. Next, the background site of this study, TARP and past studies related to it was subsequently discussed. As this study is focused on the host community, their role and significance to the park was indicated. The chapter continues by alluding the research questions and objectives of the study, the overview of methodology and method engaged, the significance and the scope of the study. A glossary of key terms used in this study was also provided for clarification purpose.

\section{Abstract of Chapter 2}

This chapter delineated the literature on the main concepts of this study comprising understanding of host community and SoP in the tourism context as well as reviewing significant theoretical models in the literature for understanding both concepts in tourism. This chapter helped build a supported argument that explore host community sense of place in tourism development for this study.

\section{Abstract of Chapter 3}

Discusses the theoretical and philosophical background as well as the rationale of the methodological decisions of the study. This chapter began by differentiating the common fuddled definitions between methodology and method. Next, it explained the three methodological questions on choosing a stance of inquiry for the study: the ontological, epistemological and axiological questions. Inquiry paradigms in the literature are briefly explained by highlighting of both positivism and interpretivism paradigm of inquiry. The chapter concludes with the methodological stance for place meanings using the quantitative approach and the qualitative approach.

\section{Abstract of Chapter 4}

The method and techniques of collecting data are presented with an illustration of research design for the study. The method for analysis including the use of ATLAS.ti 7 was also described. Additionally, this chapter also elucidated the techniques to safeguard the trustworthiness based on credibility, transferability, dependability and reflexivity of this study. 


\begin{abstract}
Chapter 5
Presents the Findings of this study. Five positive main themes with two sub-themes each and three negative themes were derived from the analysis and interpretation of the interview data that reflected the TARP host community place meanings. These themes and sub-themes were positioned within three dimensions of place based on Pearce (2005) place model and are presented in a Venn diagram. Each main theme and sub-themes were defined its elaboration through verbatim extracts from the focus group interviews as well as sample photographs elicited, and Qsorted by participants were explained through the in-depth narrative account of participants' experiences.
\end{abstract}

\section{Abstract of Chapter 6}

Addressed and discussed the research questions postulated for this study through understanding host community place experiences and their relationship to TARP. The chapter first examined the TARP Host Meanings framework within the theoretical context of existing literature, addressing the first research question of the study. Targeting the second research question of the study, the Typology of Host Community Visitors was created to represent the non-homogenous experiences of participants which indicated the relationships of host community have with TARP. The third and final research question of this study was answered through the creation of PMM to address the changes in relationships with TARP as tourism development continues.

\begin{abstract}
Chapter 7
Chapter Seven concludes the study by first revisiting the research questions and objectives of the study. Next, the theoretical, methodological and practical contribution of this study was elucidated. A critical reflection by the researcher and the limitations of the study were also explained. Essentially, recommendations were provided for future work to be conducted based on the findings of this study. I close with some final thoughts that I had for the study and TARP.
\end{abstract}

\section{References:}

Cohen, E. (1972) Toward a Sociology of International Tourism. Social Research, 39 (1), 164-182 Krippendorf, J. (1987) The Holiday Makers. Understanding the Impact of Leisure and Travel. Oxford: Butterworth Heinemann.

Doxey, G.V. (1976) When Enough's Enough: The Natives are Restless in Old Niagara. Heritage Canada 2 (2), 26-27

Pearce, P.L. (2005) Tourist Behaviour: Themes and Conceptual Schemes. Clevedon: Channel View Publications.

Stedman, R., Beckley, D., Wallace, S. \& Ambard, M. (2004) A Picture and 1000 Words: Using Resident-Employed Photography to Understand Attachment to High Amenity Places. Journal of Leisure Research, 36 (4), 580-606 